DE

M E D I C I N A

T R O P I C A L

$\mathrm{DE}$

SÃO PAULO

JOURNAL OF THE SÃO PAULO INSTITUTE OF TROPICAL MEDICINE

${ }^{1}$ Yat-sen University, Third Affiliated Hospital of Sun, Department of Dermatology and Venereology, Guangzhou, China

${ }^{2}$ Yat-sen University, Sun Yat-sen Memorial Hospital, Department of Dermatology and Venereology, Guangzhou, China

${ }^{3}$ Sun Yat-sen University, Sun Yat-sen Memorial Hospital, Guangdong Provincial Key Laboratory of Malignant Tumor Epigenetics and Gene Regulation, Guangzhou, China

*These authors contributed equally to the work.

Correspondence to: Huaiqiu Huang Yat-sen University, Third Affiliated Hospital of Sun, Department of Dermatology and Venereology, Tianhe Road, 600, Tianhe District, Guangzhou, China

Tel: +86 2085253017

Fax: +86 2085252425

E-mail: hhuaiq@mail.sysu.edu.cn

Received: 17 January 2019

Accepted: 2 May 2019

\section{Synergistic effect of terbinafine and amphotericin B in killing Fonsecaea nubica in vitro and in vivo}

\author{
Jing Zhang ${ }^{\circledR 1,2,3^{*}}$, Xiaoyan $\mathrm{Wu}^{{ }^{1 *}}$, Meirong $\mathrm{Li}^{1}$, Jiamin Huang${ }^{1}$, Songchao Yin', \\ Huaiqiu Huang ${ }^{1}$, Chun Lu', Liyan $\mathbf{X i}^{2}$
}

\section{ABSTRACT}

Chromoblastomycosis is a chronic fungal infection. Itraconazole and terbinafine are the most recommended antifungal drugs for chromoblastomycosis, while amphotericin $\mathrm{B}$ is not usually recommended. A patient with chromoblastomycosis in our hospital showed poor clinical responses to itraconazole and terbinafine. The fungus isolated from the lesions of this patient was identified as Fonsecaea nubica and numbered zssy0803. In vitro antifungal susceptibilities of $F$. nubica zssy0803 to terbinafine, amphotericin B, itraconazole, voriconazole and caspofungin were evaluated, as well as the combinations of terbinafine with the other four antifungals. The combined effect of terbinafine and amphotericin B on other 20 clinical $F$. nubica strains was also evaluated. The minimal inhibitory concentrations of terbinafine, amphotericin B, itraconazole, voriconazole and caspofungin on F. nubica zssy0803 were $0.25 \mu \mathrm{g} / \mathrm{mL}, 2 \mu \mathrm{g} / \mathrm{mL}, 1 \mu \mathrm{g} / \mathrm{mL}, 4 \mu \mathrm{g} / \mathrm{mL}$ and $8 \mu \mathrm{g} / \mathrm{mL}$, respectively. The combination of terbinafine and amphotericin B showed the lowest fractional inhibitory concentration index of 0.28 to F. nubica zssy0803 in comparison with combinations of terbinafine and the other four antifungal drugs. The combination of terbinafine and amphotericin B was also synergistic for all the other $20 \mathrm{~F}$. nubica strains. Then, the combination of oral terbinafine $(500 \mathrm{mg} /$ day $)$ and intralesional injections of amphotericin B $(1 \mathrm{mg} / \mathrm{mL})$ was used to treat this patient. After this combined therapy for 25 weeks and terbinafine monotherapy for additional 12 weeks, the patient was cured. These findings indicate for the first time that terbinafine and amphotericin B are synergistic in killing F. nubica both in vitro and in vivo.

KEYWORDS: Drug synergism. Chromoblastomycosis. Fonsecaea nubica. Terbinafine. Amphotericin B. Itraconazole. Voriconazole. Caspofungin. Antifungal. Minimal Inhibitory Concentration.

\section{INTRODUCTION}

Chromoblastomycosis (CBM) is a chronic cutaneous fungal infection, which is prevalent in tropical and subtropical regions. The common etiologic agents of CBM are the genera Fonsecaea, Phialophora and Cladophialophora ${ }^{1}$. CBM is characterized by presenting lesions with polymorphic aspect, including plaque, nodule, verrucous lesion, tumor, and scar, which are difficult to cure ${ }^{2}$. Itraconazole (ITZ) and terbinafine (TBF) are the most recommended antifungal drugs for CBM with good therapeutic effects in most $\operatorname{cases}^{3,4}$. Amphotericin B (AMB) is not usually recommended for CBM caused by Fonsecaea species because of its limited effectiveness ${ }^{5}$. However, we found a patient with a 12-year history of CBM caused by Fonsecaea nubica, who showed poor clinical responses to ITZ monotherapy, TBF monotherapy and combination therapy of TBF and ITZ. 


\section{Case report}

A 60-year-old woman living in Guangzhou, a subtropical city in South China, whose job was matchsticks making, came to our outpatient clinic with red plaques around her right ankle and lower leg in February, 2017. The lesion presented as a papule 12 years ago without any apparent reason in her right ankle skin, and then developed slowly around her right ankle and right lower leg. The patient experienced mild pain and itching. Before 2015, she had been diagnosed with fungal infection and treated with ITZ (Xi' an Janssen Pharmaceutical Co. Ltd., China) $400 \mathrm{mg} /$ day and TBF (Novartis Pharmaceutical Co. Ltd., China) $500 \mathrm{mg} /$ day in different hospitals. In the first hospital, the patient was treated with ITZ $400 \mathrm{mg} / \mathrm{day}$ for 3 months and the lesions get smaller. Then, the patient stopped taking the drug because she worried about the side effects of ITZ. She went to another hospital to ask for "safer" drugs. In the second hospital, she was treated with TBF $500 \mathrm{mg} /$ day and the lesions continued to get smaller. After 4 months of TBF treatment, the patient stopped taking the medicine regularly because she moved far away from hospitals. Since then, she began self-medication with TBF or ITZ. The lesions had regressed gradually until 2013, but new lesions have appeared since 2013. From March 2015, she began to take medications regularly. She was treated with ITZ (400 mg/day) for 6 months, TBF $(500 \mathrm{mg} /$ day) for 6 months, and TBF (500 mg/day) combined with ITZ (400 mg/day) for 6 months successively. However, no apparent clinical response was achieved. Then, the patient stopped taking ITZ and TBF and came to our hospital. The physical examination revealed red plaques and pigmentation around her right ankle and lower leg. The boundaries of these plaques were clear. Scales and dark spots were visible on the surface of the plaques (Figure 1A-1C). Direct examination of skin scrapings revealed brown, round and thick-walled sclerotic bodies (Figure 1D). A sample from the skin lesion was inoculated in Sabouraud Dextrose Agar (Difco, Detroit, USA) at $25{ }^{\circ} \mathrm{C}$. Seven days later, velvety dark colonies were observed (Figure $1 \mathrm{E}$ and $1 \mathrm{~F}$ ). Conidia production was obtained after 14 days incubation at $25^{\circ} \mathrm{C}$ in potato agar using a microculture technique. Microscopic examination of the fungus revealed septate hyphae and conidiophores that were highly branched at the apices (Figure 1G). DNA of the fungus was extracted according to a method previously described ${ }^{6}$. The ribosomal DNA internal transcribed spacer (ITS) sequence was obtained using ITS- 1 primer and ITS-4 primer. The PCR conditions were $95{ }^{\circ} \mathrm{C}$ for $4 \mathrm{~min}$, followed by 30 cycles at $94{ }^{\circ} \mathrm{C}$ for $60 \mathrm{~s}, 55^{\circ} \mathrm{C}$ for $90 \mathrm{~s}, 72{ }^{\circ} \mathrm{C}$ for $90 \mathrm{~s}$, and a final $10 \mathrm{~min}$ extension at $72{ }^{\circ} \mathrm{C}$. The sequence was compared with the
ITS sequences from GenBank and the on-line database MycoBank. The ITS sequence of our isolate showed 99\% similarity with sequences of five $F$. nubica strains including CBS 269.64, which is the prototype strain of $F$. nubica. In addition, a phylogenetic analysis using a neighbor-joining method with known sequences of three sibling Fonsecaea species was performed to investigate interrelationships among the species. Our isolate was clustered in the F. nubica clade (Figure 2). Finally, the fungus was identified as F. nubica and named zssy0803 (GenBank ${ }^{\circ}$ MH012177). Histological examination of lesions showed hyperkeratosis, parakeratosis and granulomatous inflammation in the dermal layers (Figure 1H). Sclerotic bodies were observed in the multinucleated giant cells (Figure 1I). Blood routine, chest $\mathrm{X}$-ray and electrocardiogram showed no abnormalities. Both anti-HIV antibody and specific syphilis antibody tests were negative. $\mathrm{CD} 4+\mathrm{T}$ cells and CD8+ T cells counts were in the normal range. Considering the clinical features and testing results, the patient was diagnosed with CBM caused by $F$. nubica.

To get more drug sensitivity information and find a better treatment method for the patient, in vitro antifungal susceptibilities of $F$. nubica strains to antifungal drugs were investigated.

\section{MATERIALS AND METHODS}

\section{Microorganisms}

F. nubica zssy0803 and other 20 clinical F. nubica strains preserved in our lab were prepared for antifungal susceptibility testing in vitro. Candida parapsilosis (ATCC 22019) was used for the quality control.

\section{Antifungal drugs and susceptibility testing}

Five antifungal drugs including AMB (GLTSCIENCES, Wuhan, China), ITZ (Shifeng, Shanghai, China), TBF (Yansheng, Shanghai, China), voriconazole (VCZ, SinoStandards, Chengdu, China) and caspofungin (Shifeng, Shanghai, China) were used for antifungal susceptibility testing of the strain zssy0803. Susceptibilities of $F$. nubica zssy0803 to TBF in combination with AMB, ITZ, VCZ and CAS were evaluated. Susceptibilities of the other 20 F. nubica strains to TBF in combination with AMB were also evaluated. Drugs were dissolved in dimethyl sulphoxide (Shifeng, Shanghai, China) to obtain the stock concentration of $6,400 \mu \mathrm{g} / \mathrm{mL}$. The final concentrations of antifungal agents ranged from $0.0078-4 \mu \mathrm{g} / \mathrm{mL}$ for TBF, $0.0313-16 \mu \mathrm{g} / \mathrm{mL}$ for ITZ, VCZ, and AMB, and $0.0625-32 \mu \mathrm{g} / \mathrm{mL}$ for CAS. 


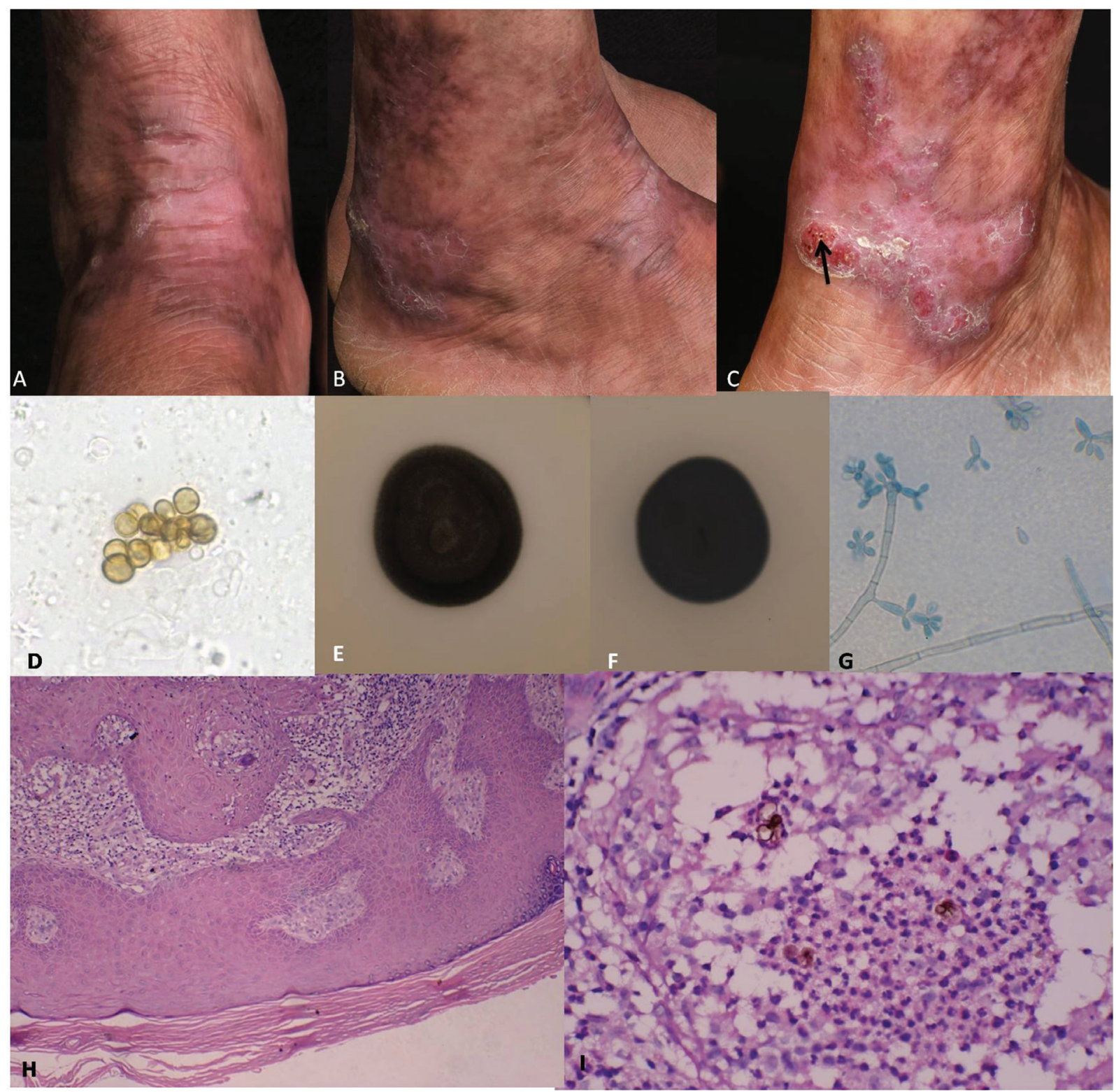

Figure 1 - F. nubica zssy0803 (A-C): Red plaques around the right ankle and lower leg of the patient before the treatment in our hospital. The black arrow points to dark spots on the surface of the plaques; (D) Brown, round and thick-walled sclerotic bodies in the direct examination of skin scrapings; $(\mathrm{E}-\mathrm{F})$ Velvety dark colony in Sabouraud Dextrose Agar on the $7^{\text {th }}$ day of inoculation. $1 \mathrm{E}$ is the verse side and $1 \mathrm{~F}$ is the reverse of the colonies; $(\mathrm{G})$ Conidia production obtained after 14 days of incubation at $25^{\circ} \mathrm{C}$ in potato agar using a microculture technique. Septate hyphae and conidiophores highly branching at the apices (lactophenol cotton blue stain, 400x). (H) Hyperkeratosis, parakeratosis, and granulomatous inflammation in dermal to superficial dermal layers (hematoxylin and eosin stain, 40x). Sclerotic bodies observed in the cytoplasm of multinucleated giant cells (hematoxylin and eosin stain, 400x).

Antifungal susceptibility testing was carried out using a broth microdilution method according to Clinical and Laboratory Standards Institute guideline M38-A2 ${ }^{7}$. All the F. nubica strains were cultured in potato dextrose agar (BD, Franklin Lakes, NJ, USA) for 7 days at $35^{\circ} \mathrm{C}$, and suspensions were prepared by scraping the surface of fungal colonies with a pipette and $1 \mathrm{~mL}$ of $0.85 \%$ sterile saline containing $0.01 \mathrm{~mL}$ Tween 20 (Shifeng, Shanghai, China). Then, suspensions were kept stationary for $5 \mathrm{~min}$ at room temperature to decant particles. Each suspension was diluted with RPMI 1640 to obtain the $2 \times$ final test inoculum $\left(4 \times 10^{4} \mathrm{CFU} / \mathrm{mL}\right)$ using a hemocytometer. Plates were incubated at $35^{\circ} \mathrm{C}$ for 5 days. The minimal inhibitory concentration (MIC) was defined as $100 \%$ inhibition of fungi growth in the drug well, in comparison with that in the growth control well. The minimal effective concentration (MEC) for CAS was defined as the minimal effective concentration that lead to growth of small, rounded and compact hyphal forms in comparison with that in the growth control well. 


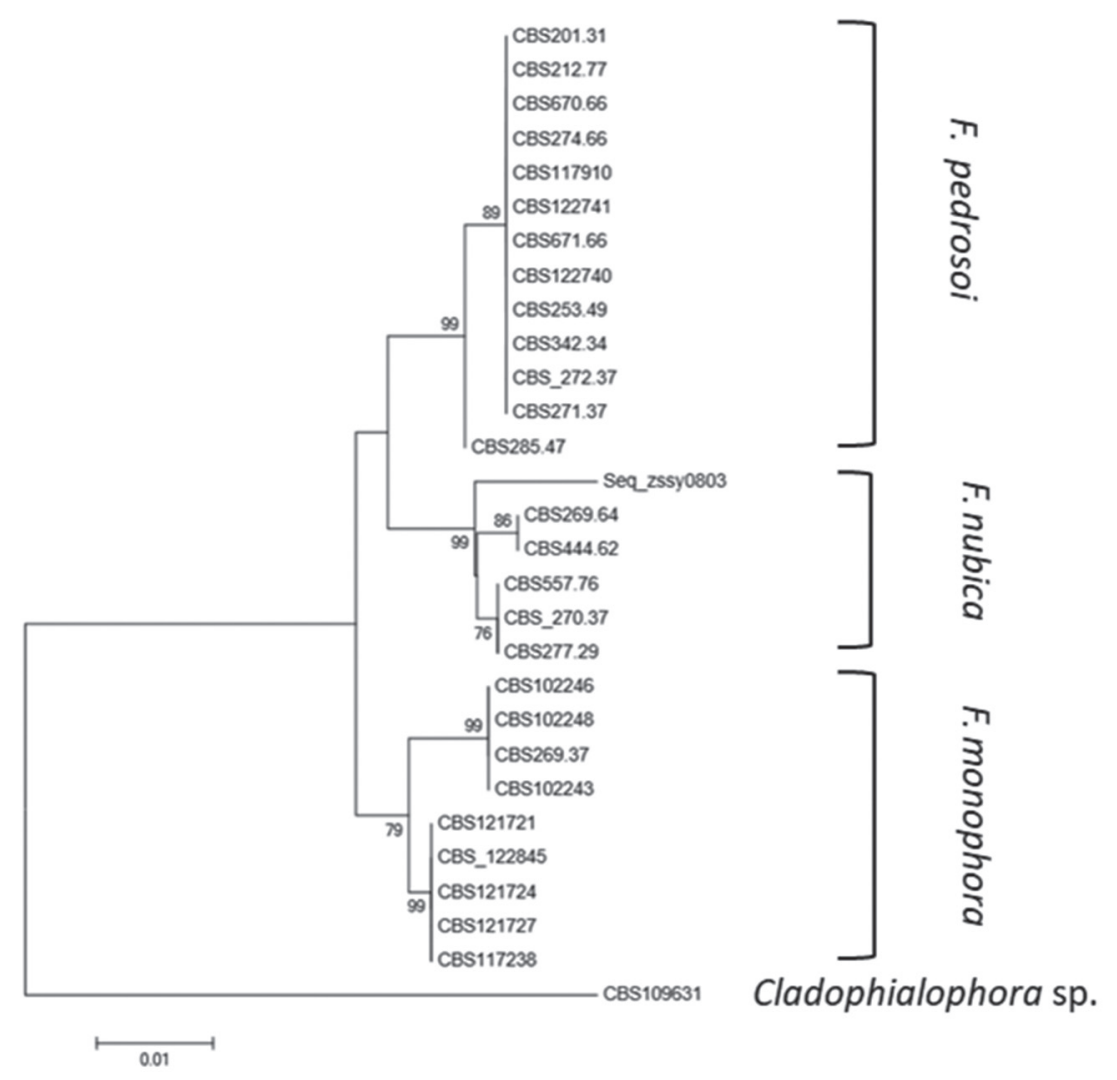

Figure 2 - Phylogenetic trees of Fonsecaea species based on confidently aligned internal transcribed spacer sequences constructed using the neighborjoining implemented in MEGA 6.0. A Cladophialophora species was used as the outgroup. Origin and location of the clinically relevant Fonsecaea species were indicated next to the strain number. CBS269.64 was the prototype strain of the species.

The susceptibility testing of $F$. nubica to antifungal drug combinations was conducted using the checkerboard method $^{8}$. The interaction coefficient among drugs was quantitatively evaluated by means of the fractional inhibitory concentration index (FICI). The interaction was defined as synergistic if the FICI $\leq 0.5$, no interaction if the FICI $>0.5$ and $\leq 4.0$, and antagonistic if the FICI $>4.0^{9,10}$.

\section{RESULTS}

\section{In vitro antifungal susceptibility testing}

The susceptibility testing results of $F$. nubica zssy0803 to TBF, ITZ, VCZ, AMB and combined drugs are summarized in Table 1. The MIC was $0.25 \mu \mathrm{g} / \mathrm{mL}$ for TBF, $2 \mu \mathrm{g} / \mathrm{mL}$ for ITZ, and $4 \mu \mathrm{g} / \mathrm{mL}$ for AMB. The susceptibility testing of F. nubica zssy0803 to the combination of TBF and AMB showed the lowest FICI (0.28) and was compared with other antifungal drug combinations, which indicated synergism of TBF and AMB for F. nubica zssy0803 in vitro. VCZ and TBF have also shown a synergistic effect for $F$. nubica zssy0803 in vitro. The susceptibility testing results of other $20 \mathrm{~F}$. nubica strains to TBF combined with AMB are summarized in Table 2. FICIs among TBF and $\mathrm{AMB}$ to the $20 \mathrm{~F}$. nubica strains were $\leq 0.5$, which indicated a synergic effect of TBF and AMB for F. nubica in vitro.

Table 1 - In vitro susceptibility test results of Fonsecaea nubica zssy0803 strains to five antifungal drugs.

\begin{tabular}{|c|c|c|c|c|c|c|c|c|c|c|c|c|c|c|c|c|c|c|c|}
\hline \multicolumn{4}{|c|}{$\mathrm{MIC}(\mu \mathrm{g} / \mathrm{mL})$} & \multirow{3}{*}{$\mathrm{FICl}$} & \multicolumn{4}{|c|}{$\mathrm{MIC}(\mu \mathrm{g} / \mathrm{mL})$} & \multirow{3}{*}{$\mathrm{FICl}$} & \multicolumn{4}{|c|}{$\mathrm{MIC}(\mu \mathrm{g} / \mathrm{mL})$} & \multirow{3}{*}{$\mathrm{FICl}$} & \multicolumn{4}{|c|}{ 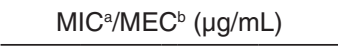 } & \multirow{3}{*}{$\mathrm{FICl}$} \\
\hline \multicolumn{2}{|c|}{ Single drug } & \multicolumn{2}{|c|}{ Combination } & & \multicolumn{2}{|c|}{ Single drug } & \multicolumn{2}{|c|}{ Combination } & & \multicolumn{2}{|c|}{ Single drug } & \multicolumn{2}{|c|}{ Combination } & & \multicolumn{2}{|c|}{ Single drug } & \multicolumn{2}{|c|}{ Combination } & \\
\hline TBF & AMB & TBF & AMB & & TBF & ITZ & TBF & ITZ & & TBF & VCZ & TB & VCZ & & TBF & CAS & TBF & CAS & \\
\hline 0.25 & 4 & 0.0078 & 1 & 0.28 & 0.25 & 2 & 0.125 & 1 & 1 & 0.25 & 1 & 0.0625 & 0.25 & 0.5 & 0.25 & 8 & 0.125 & 8 & 1.5 \\
\hline
\end{tabular}

MIC: minimal inhibitory concentration; MEC: minimal effective concentration; FICl: fractional inhibitory concentration index (values were interpreted as follows: $\mathrm{FICl} \leq 0.5$, synergism; $0.5<\mathrm{FICl} \leq 4$, indifference; and $\mathrm{FICl}>4$, antagonism); TBF: terbinafine; AMB: amphotericin B; ITZ: itraconazole; $\mathrm{VCZ}$ : voriconazole; CAS: caspofungin. ${ }^{a} \mathrm{MIC}$ is for TBF. ${ }^{\mathrm{b}} \mathrm{MEC}$ is for CAS. 
Table 2 - In vitro susceptibility test results of 20 Fonsecaea nubica strains to Terbinafine and Amphotericin B.

\begin{tabular}{|c|c|c|c|c|c|c|c|c|c|c|c|}
\hline \multicolumn{10}{|c|}{ MIC $(\mu \mathrm{g} / \mathrm{mL})$} & \multicolumn{2}{|c|}{$\mathrm{FICl}$} \\
\hline \multicolumn{2}{|c|}{$\begin{array}{c}\text { GM of single } \\
\text { drug }\end{array}$} & \multicolumn{2}{|c|}{$\begin{array}{c}\text { MIC50 of single } \\
\text { drug }\end{array}$} & \multicolumn{2}{|c|}{$\begin{array}{c}\text { MIC90 of single } \\
\text { drug }\end{array}$} & \multicolumn{2}{|c|}{$\begin{array}{c}\text { Range of single } \\
\text { drug }\end{array}$} & \multicolumn{2}{|c|}{$\begin{array}{c}\text { Range of drug in } \\
\text { combination }\end{array}$} & \multirow{2}{*}{ Range } & \multirow{2}{*}{ GM } \\
\hline TBF & AMB & TBF & AMB & TBF & AMB & TBF & AMB & TBF & AMB & & \\
\hline 0.167 & 3.138 & 0.25 & 2 & 0.5 & 16 & $0.0313-0.5$ & $0.5-16$ & $0.0078-0.125$ & $0.125-4$ & $0.19-0.5$ & 0.36 \\
\hline
\end{tabular}

$\mathrm{FICl}$ : fractional inhibitory concentration index (values were interpreted as follows: $\mathrm{FICl} \leq 0.5$, synergism; $0.5<\mathrm{FICl} \leq 4$, indifference; and $\mathrm{FICl}>$ 4, antagonism); MIC: the minimal inhibitory concentration; GM: geometrical mean; TBF: terbinafine; AMB: amphotericin B.

\section{Combination therapy of TBF and AMB in the patient}

The patient was treated with $\mathrm{TBF}(500 \mathrm{mg} /$ day $)$ and intralesional injections of AMB (North China Pharmaceutical Co., Ltd., China). Twenty-five milligrams of AMB were dissolved in $20 \mathrm{~mL}$ of sterilized water, and then, $5 \mathrm{~mL}$ of $2 \%$ lidocaine solution were added to the AMB solution. The final concentration of the AMB solution was $1 \mathrm{mg} / \mathrm{mL}$. The AMB solution was injected intralesionally once every two weeks except for a 3 -week interval between the first and the second injection and 0.25-0.5 mL of AMB solution was used per square centimeter of lesion. After 25 weeks of treatment with $\mathrm{TBF}$ and $\mathrm{AMB}$, the red plaques around the ankle and the right leg of the patient disappeared. Hypopigmentation, hyperpigmentation and atrophic scars were observed on the patient's right ankle and lower leg (Figure 3). Fungal forms were not found either on microscopic examination of scrapings or biopsy, and then, AMB was interrupted (twelve injections and a total of $256 \mathrm{mg}$ of AMB had been given during 25 weeks). The patient was afterwards treated with TBF (500 mg/day) for 12 weeks. A microscopic examination and a biopsy were performed again one week before TBF interruption and no fungal elements were found in the skin. The patient was followed-up until nowadays and no lesions relapsed. During the treatment and follow-up period, renal, liver and cardiovascular function of the patient were normal.

\section{DISCUSSION}

Although there is not a drug or therapy of choice, ITZ has shown the best results for $\mathrm{CBM}^{11-13}$. TBF also has been proved to be very effective $e^{4,14-16}$. The combination therapy of ITZ and TBF is usually used in patients presenting refractory lesions ${ }^{6,17-20}$. In previous reports, ITZ and TBF showed good responses to treat CBM caused by $F$. nubica $^{17,21}$. This is the first case report on CBM caused by F. nubica which was not responsive to ITZ and TBF. This insensitivity may be induced by irregular medicine taking during the 10 years prior to the arrival to our hospital, since the patient showed good responses to ITZ and TBF at the early stage of the disease. The total dosage of TBF and ITZ that the patient had taken before 2015 cannot be calculated, since the patient could not provide precise information.

The susceptibility testing of $F$. nubica zssy0803 showed a MIC of $0.25 \mu \mathrm{g} / \mathrm{mL}$ for TBF and $2 \mu \mathrm{g} / \mathrm{mL}$ for ITZ. There are no recommended standards for the susceptibility testing result of Fonsecaea species. However, in comparison with previous antifungal susceptibility testing results for

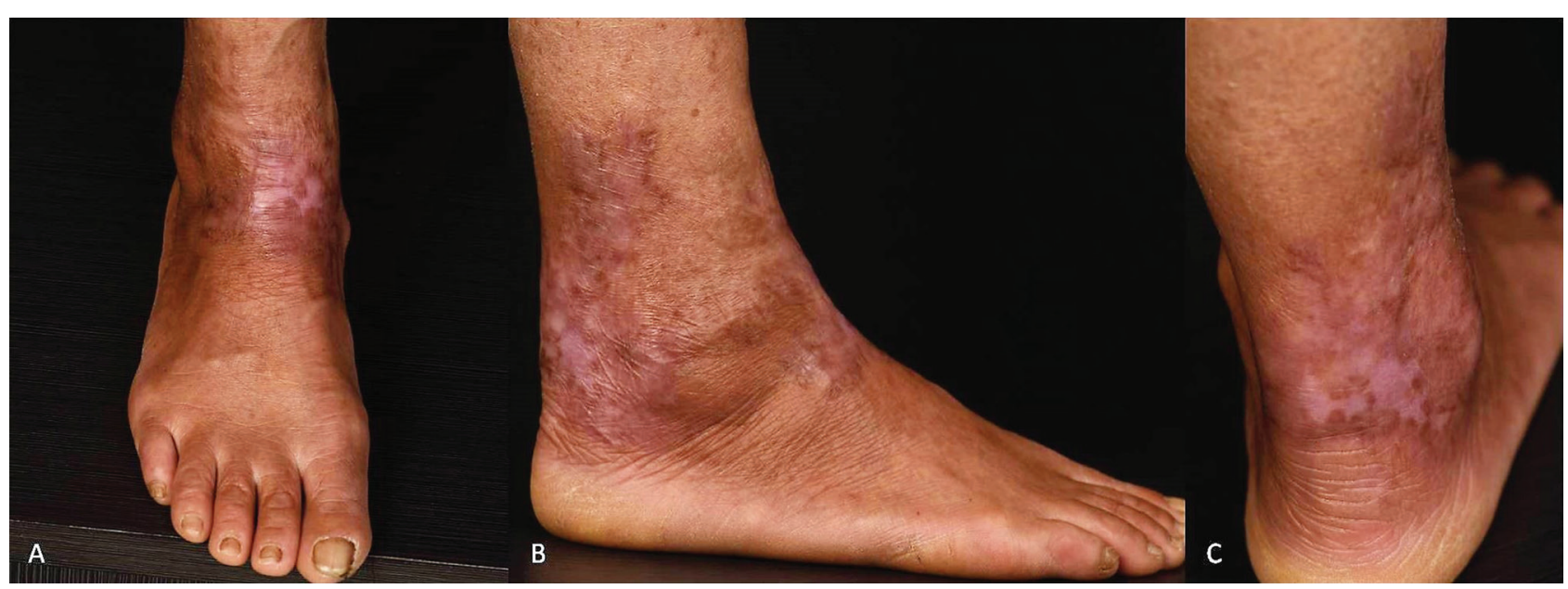

Figure 3 - Aspect of the right ankle and the lower leg of the patient with chromoblastomycosis caused by F. nubica zssy0803 after treatment with the combination of amphotericin $B$ and terbinafine $(A-C)$. 
Fonsecaea species, both MIC of TBF and MIC of ITZ for F. nubica zssy0803 were higher ${ }^{6,8}$. VCZ could be useful to this patient since it has been proved to be effective to refractory $\mathrm{CBM}^{22}$. However, this patient was poor and could not afford a VCZ treatment. Interestingly, a in vitro synergistic effect of TBF and AMB for F. nubica zssy0803 was observed in susceptibility tests. We then used other 20 F. nubica clinical isolates to evaluate the combined effect of TBF and AMB, although TBF and AMB were not used for these 20 strains in vivo. A synergistic effect of TBF and AMB was also observed for every strain. Therefore, the synergistic effect of TBF and AMB for F. nubica zssy0803 was not accidental. These results were consistent with those of previous studies ${ }^{5,23,24}$. AMB is a cheap antifungal drug used to treat CBM due to Fonsecaea species before triazoles have emerged ${ }^{25-28}$. The monotherapy with AMB for Fonsecaea species has not been used due to its limited success and side effects ${ }^{29}$. However, considering the in vitro synergistic effect and economic status of the patient, the combination therapy of TBF and AMB was used.

To reduce the side effects of the intravenous administration, a small amount of AMB was used intralesionally. In a previous study, AMB solution was used intralesionally for CBM at a $0.25 \mathrm{mg}-0.5 \mathrm{mg}$ per square centimeter dose and this was repeated three times, weekly ${ }^{28}$. In this study, the same type of AMB was used in a longer treatment interval since it took two to three weeks for the regression of swelling and blisters in the AMB injection sites.

The MICs $\leq 1 \mu \mathrm{g} / \mathrm{mL}$ are generally used as an indicator of a potential susceptibility to most drugs used in the treatment of infections caused by black molds ${ }^{30}$. In this study, the MIC of AMB for F. nubica zssy0803 was $4 \mu \mathrm{g} / \mathrm{mL}$, which indicated that $F$. nubica zssy 0803 was probably insensitive to $\mathrm{AMB}$ alone in vivo. In addition, $\mathrm{AMB}$ was used in the patient once every two or three weeks. The intervals were longer than the recommended ones according to the manufacturer. Considering these points, we concluded that killing of $F$. nubica zssy0803 in vivo was primarily due to the synergistic effect of TBF and AMB, and not to the effect of AMB alone. TBF reduces the ergosterol biosynthesis by inhibiting the squalene epoxidase, an enzyme that catalyzes the conversion of squalene to lanosterol ${ }^{31}$. The mechanisms of AMB action are pore formation after binding to the ergosterol present in the membrane, inducing an oxidative damage in the fungal cells and modulating the immune system of host cells ${ }^{32,33}$. The synergistic effect of TBF and $\mathrm{AMB}$ in vivo may be the consequence of different mechanisms acting together.

TBF and VCZ have also shown a synergistic effect for F. nubica zssy0803 in vitro. This result was similar to the ones of a previous study ${ }^{34}$. The mechanism of VCZ, similar to ITZ, is the inhibition of the cytochrome P450-dependent $14 \alpha$-lanosterol demethylation, which is a vital step in cell membrane ergosterol biosynthesis of fungi ${ }^{35}$. The synergistic effect is primarily due to be co-inhibition of ergosterol biosynthesis by TBF and VCZ.

These findings indicate, for the first time that TBF and AMB are synergistic in killing $F$. nubica both in vitro and in vivo. The combination therapy of TBF and $\mathrm{AMB}$ could be an inexpensive alternative for the treatment of CBM patients that fail to respond to first-line drugs.

\section{ACKNOWLEDGMENTS}

This work was kindly supported by the National Science Foundation of China ( ${ }^{\circ}$ 81371746). We thank Xuebing Leng from Georgetown University for the language editing.

\section{CONFLICT OF INTERESTS}

The authors declare no potential conflict of interest.

\section{REFERENCES}

1. Queiroz-Telles F, de Hoog S, Santos DW, Salgado CG, Vicente VA, Bonifaz A, et al. Chromoblastomycosis. Clin Microbiol Rev. 2017;30:233-76.

2. Brito AC, Bittencourt MJ. Chromoblastomycosis: an etiological, epidemiological, clinical, diagnostic, and treatment update. An Bras Dermatol. 2018;93:495-506.

3. Yang YP, LiW, Huang WM, Zhou Y, Fan YM. Chromoblastomycosis caused by Fonsecaea: clinicopathology, susceptibility and molecular identification of seven consecutive cases in Southern China. Clin Microbiol Infect. 2013;19:1023-8.

4. Silva-Rocha WP, Cardoso FJ, Colalto W, Melo AS, Chaves GM. Clinical improvement of chromoblastomycosis refractory to itraconazole successfully treated with high dose of terbinafine. J Dermatol. 2013;40:775-6.

5. Daboit TC, Massotti Magagnin C, Heidrich D, Czekster Antochevis L, Vigolo S, Collares Meirelles L, et al. In vitro susceptibility of chromoblastomycosis agents to five antifungal drugs and to the combination of terbinafine and amphotericin B. Mycoses. 2014;57:116-20.

6. He L, Ma J, Mei X, Lu S, Li X, Xi L. Successful treatment of chromoblastomycosis of 10-year duration due to Fonsecaea nubica. Mycoses. 2018;61:231-6.

7. Clinical and Laboratory Standards Institute. Reference method for broth dilution antifungal susceptibility testing of filamentous fungi: approved standard. $2^{\text {nd }}$ ed. Wayne: CLSI; 2008.

8. Yu J, Li R, Zhang M, Liu L, Wan Z. In vitro interaction of terbinafine with itraconazole and amphotericin B against 
fungi causing chromoblastomycosis in China. Med Mycol. 2008;46:745-7.

9. Argenta JS, Santurio JM, Alves SH, Pereira DI, Cavalheiro AS, Spanamberg A, et al. In vitro activities of voriconazole, itraconazole, and terbinafine alone or in combination against Pythium insidiosum isolates from Brazil. Antimicrob Agents Chemother. 2008;52:767-9.

10. Daboit TC, Duquia RP, Magagnin CM, Mendes SD, Castrillón MR, Steglich R, et al. A case of Exophiala spinifera infection in Southern Brazil: molecular identification and antifungal susceptibility. Med Mycol Case Rep. 2012;1:72-5.

11. Bonifaz A, Carrasco-Gerard E, Saúl A. Chromoblastomycosis: clinical and mycologic experience of 51 cases. Mycoses. 2001;44:1-7.

12. Queiroz-Telles F, Esterre P, Perez-Blanco M, Vitale RG, Salgado CG, Bonifaz A. Chromoblastomycosis: an overview of clinical manifestations, diagnosis and treatment. Med Mycol. 2009;47:3-15.

13. Queiroz-Telles F, Santos DW. Challenges in the therapy of chromoblastomycosis. Mycopathologia. 2013;175:477-88.

14. Hu Y, Huang X, Lu S, Hamblin MR, Mylonakis E, Zhang J, et al. Photodynamic therapy combined with terbinafine against chromoblastomycosis and the effect of PDT on Fonsecaea monophora in vitro. Mycopathologia. 2015;179:103-9.

15. Bassas-Vila J, Fuente MJ, Guinovart R, Ferrándiz C. Chromoblastomycosis: response to combination therapy with cryotherapy and terbinafine. Actas Dermosifiliogr. 2014;105:196-8.

16. Xibao Z, Changxing L, Quan L, Yuqing H. Treatment of chromoblastomycosis with terbinafine: a report of four cases. J Dermatolog Treat. 2005;16:121-4.

17. Chen Y, Yin S, Li M, Chen R, Wei L, Ma H, et al. A case of chromoblastomycosis by Fonsecaea nubica indicating a possible insect route of transmission. Mycoses. 2016;59:662-7.

18. Tan H, Xu Y, Lan XM, Wu YG, Zhou CJ, Yang XC. Chromoblastomycosis due to Fonsecaea monophora in a man with nephritic syndrome. Mycopathologia. 2015;179:447-52.

19. Zhang J, Xi L, Lu C, Li X, Xie T, Zhang H, et al. Successful treatment for chromoblastomycosis caused by Fonsecaea monophora: a report of three cases in Guangdong, China. Mycoses. 2009;52:176-81.

20. Gupta AK, Taborda PR, Sanzovo AD. Alternate week and combination itraconazole and terbinafine therapy for chromoblastomycosis caused by Fonsecaea pedrosoi in Brazil. Med Mycol. 2002;40:529-34.

21. Slesak G, Inthalad S, Strobel M, Marschal M, Hall M, Newton PN. Chromoblastomycosis after a leech bite complicated by myiasis: a case report. BMC Infect Dis. 2011;11:14.
22. Criado PR, Cosenza FD, Junior WB, Ferreira PS. Longitudinal melanonychia due to voriconazole therapy during treatment of chromoblastomycosis. Clin Exp Dermatol. 2018;43:75-6.

23. Daboit TC, Magagnin CM, Heidrich D, Castrillón MR, Mendes $\mathrm{SD}$, Vettorato G, et al. A case of relapsed chromoblastomycosis due to Fonsecaea monophora: antifungal susceptibility and phylogenetic analysis. Mycopathologia. 2013;176:139-44.

24. Deng S, Lei W, de Hoog GS, Yang L, Vitale RG, Rafati H, et al. Combination of amphotericin B and terbinafine against melanized fungi associated with chromoblastomycosis. Antimicrob Agents Chemother. 2018;62:e00270-18.

25. Clark RF. Chromoblastomycosis of the ear. Successful intralesional therapy with amphotericin B. Cutis. 1979;24:326-8.

26. Whiting DA. Treatment of chromoblastomycosis with high local concentrations of amphotericin B. Br J Dermatol. 1967;79:34551.

27. Astorga E, Bonilla E, Martínez C, Mura W. Tratamiento de la cromoblastomicosis con anfotericina B y 5-fluorocitosina. Med Cutan Ibero Lat Am. 1981;9:125-8.

28. Derbes VJ, Friedman L, Krafchuk JD. Chromoblastomycosis treated by vibrapuncture injection of amphotericin B. Arch Dermatol. 1959;80:286-7.

29. Laniado-Laborín R, Cabrales-Vargas MN. Amphotericin B: side effects and toxicity. Rev Iberoam Micol. 2009;26:223-7.

30. Revankar SG, Sutton DA. Melanized fungi in human disease. Clin Microbiol Rev. 2010;23:884-928.

31. Elewski BE. Mechanisms of action of systemic antifungal agents. J Am Acad Dermatol. 1993;28:S28-34.

32. Mesa-Arango AC, Trevijano-Contador N, Román E, SánchezFresneda R, Casas C, Herrero E, et al. The production of reactive oxygen species is a universal action mechanism of Amphotericin B against pathogenic yeasts and contributes to the fungicidal effect of this drug. Antimicrob Agents Chemother. 2014;58:6627-38.

33. Mesa-Arango AC, Scorzoni L, Zaragoza O. It only takes one to do many jobs: Amphotericin B as antifungal and immunomodulatory drug. Front Microbiol. 2012;3:286.

34. Biancalana FS, Lyra L, Schreiber AZ. In vitro evaluation of the type of interaction obtained by the combination of terbinafine and itraconazole, voriconazole, or amphotericin B against dematiaceous molds. Antimicrob Agents Chemother. 2011;55:4485-7.

35. Johnson LB, Kauffman CA. Voriconazole: a new triazole antifungal agent. Clin Infect Dis. 2003;36:630-7. 